\title{
Industry Forum III: Towards A Common Language
}

\author{
K. Ferens, J. Seniuk Cicek, N. Sepehri, W. Kinsner, J.P. Burak, A. Parker, \\ D. McNeill, D. Ruth, I. Jeffrey, N. Godavari, S. Ingram \\ Dept. of Electrical and Computer Engineering, University of Manitoba, Winnipeg, MB, Canada \\ Ken.Ferens@umanitoba.ca
}

\begin{abstract}
Engineering Education literature acknowledges that the language Academia uses to assess the abilities of engineering students may not be the same as the language Industry uses to measure the abilities of new graduates at the time they enter the work force. It also suggests that the understanding and expectations of Industry may differ from Academia. If the language, perceptions and expectations are different, so too could be Industry's assessment of the knowledge, skills and attitudes of new engineering graduates. Consequently, Industry may need to spend additional resources to develop the abilities of new hires to meet their own needs. The Industry Forum III was conducted in partnership with members of Manitoba Industry and members of Academia from the Faculty of Engineering at the University of Manitoba with the objective to develop a common language that Industry and Academia can use in concert to measure the abilities of new engineering graduates. This paper details the findings from the forum, as well as the changes made to the University of Manitoba graduate attribute rubrics in the pursuit of a common language for our engineering stakeholders.
\end{abstract}

Keywords: Industry forum; $\mathrm{CEAB}$ attributes; Common language; Assessment

\section{INTRODUCTION}

Academics continually seek opinions regarding the attributes required of their students, especially in fields that change rapidly with technology [1]. Sources of feedback include other academic researchers; journal and conference papers; students; alumni; and local, national, and global industries. Perhaps, one of the best resources for graduate attribute feedback is Industry. At the University of Manitoba, and at other universities around the world, a majority of engineering graduates proceed to work in Industry [2]. Therefore, it makes sense that an engineering faculty should make all efforts to educate their students to meet Industry's needs. However, the literature suggests that differences lie between the understanding and expectations of Academics and Industry in regards to the abilities and employability of graduates: "...the research literature strongly indicates that, while progress has been made concerning HEI [Higher Education Institutions] responses to employers' needs, there is still much to be done to foster a shared understanding across employers, HEI and other stakeholders of graduate employability and how to promote it. Indeed, our scoping study and literature review revealed that while there are examples of employers and HEIs working to promote graduate employability, there are still significant issues in terms of differences in mindset and expectations between some HEIs, employers and other stakeholders" [3]. The literature also suggests that differences lie between the language Academics use and the language Industry uses [4]. If the perceptions and expectations of Academics and Industry are different, and the language is different, so too could be their assessments of the knowledge, skills and attitudes of new graduates at the time they enter the work force. To establish a meaningful link between Academia and Industry's expectations and assessments of engineering graduates, and before any significant analysis of engineering graduate students in regards to the Canadian Engineering Accreditation Board (CEAB) attributes [5] can be done, a common understanding and language must be established [6] [7]. Towards this end, the Industry Forum III, sponsored by the Faculty of Engineering at the University of Manitoba, was initiated.

The guiding reason for having an Industry forum is to support and contribute to the betterment of engineering education by providing an unbiased, external and third party appraisal of the engineering curriculum, and ultimately graduate more productive, efficient and competitive Industryready engineers. A forum that brings Engineering Industry and Academia together enables Academia to explore Industry's expectations and experiences of new graduates [8] [9] with regards to the $12 \mathrm{CEAB}$ attributes. Strengths can be acknowledged and gaps can be addressed, demonstrating the Faculty's partnership and accountability to local Industry. In addition, the forum helps Academia identify the key attributes that make engineering employees best in class in their field, with the intention to strengthen these attributes in students through the improvement of the engineering curricula.

A partial requirement of becoming accredited by the CEAB is that engineering faculties have processes in place to assess their program outcomes in the context of the 12 graduate attributes, and that the results are applied to the continual development and improvement of their curricula [6] [8] [9]. The Industry forum is such a process, whereby Industry representatives discuss and critique the $\mathrm{CEAB}$ attributes exhibited by new engineering graduates, as well as the faculty's assessment tools and processes, and the results of these 
discussions are sent to the Faculty's Curriculum Management Committee (CMC) to analyze for the development and improvement of the engineering programs. The Faculty has established this cycle as a continuous process, with integrated assessments (Industry forum) and improvements (CMC) occurring several times per year in keeping with the fulfillment of the new CEAB accreditation requirements.

The Industry Forum III took place on 9 December 2013, and consisted of three phases. In preparation for the forum, Industry participants were provided with a survey, which was constructed from a set of rubrics created by Academia to assess the abilities of engineering students at various levels of development in their programs, as well as new graduates as they enter the workforce in regards to the $12 \mathrm{CEAB}$ graduate attributes [10]. The survey was designed to get Industry's feedback on the indicators and competency levels of four of the CEAB graduate attributes: Problem Analysis, Use of Engineering Tools, Ethics and Equity, and Economics and Project Management. Participants were asked to select a competency level for each indicator of an attribute that they believed an engineering student should exhibit (Phase 1). In Phase 2, Industry participants were invited to modify the wording of the indicators and competency levels to reflect the language used in their industry. In Phase 3, Industry and Academia met in person to discuss the targeted attributes and Industry's modifications.

Approximately 30 Industry and 17 Academic representatives attended the forum. Industry participants (both offline and forum attendees) were from the following industries: Atomic energy, Construction, Biosystems, Manufacturing, Electrical Power Systems, Automotive, Hydropower Supply and Services, Embedded Systems, Aerospace, Electronics Products and Services, Bio-systems Engineering, Civil Engineering, Computer Engineering, Electrical Engineering, Mechanical Engineering, Architecture, Consultation, Software Engineering, Transportation, Education, Health Services and Supply, Information Engineering Products and Services, Computer Network and Information Security, Telecommunications, and Information Technology. The names of the companies and Industry participants were not recorded to maintain anonymity. Academic representatives included the Associate Dean (Undergraduate Programs), seven Department and Associate Heads, and eight professors from the five Engineering programs at the University of Manitoba: Biosystems, Civil, Electrical and Computer and Mechanical Engineering, as well as one doctoral student with a focus in engineering education.

The Industry Forum III represents a continuation of the ongoing partnership between local Manitoba Industry and Academia from the Faculty of Engineering at the University of Manitoba, with the singular goal of improving engineering education. In particular, this forum, the third in a sequence of Industry forums held so far, initiated work to establish a common language that both partners can agree upon to assess engineering students and new engineering graduates. It is a step towards the process of creating a common assessment tool for engineering stakeholders in regards to the $12 \mathrm{CEAB}$ graduate attributes.

\section{PROCEDURE}

The Industry Forum III consisted of three phases: Phase 1 and Phase 2 were completed offline and prior to the participants attending the forum itself in Phase 3.

\subsection{Phase 1: Survey}

The participants were asked to complete a given survey and return it to the facilitator on or before December 5 . The survey was created in a clickable PDF format (contact the first author for an example). It demonstrated the indicators and the language Academia could use to measure the expected outcomes of new engineering graduates in regards to the attributes Problem Analysis, Use of Engineering Tools, Ethics and Equity, Economics and Project Management. The participants were asked to fill out the survey as best as possible, even if it did not reflect the language used by Industry, by choosing the competency level for each indicator that they felt an engineering student should exhibit at the time of graduation.

\subsection{Phase 2: Industry Input}

In Phase 2, participants were asked to prepare for the forum by analyzing the given survey to modify, delete and/or add indicators and competency levels to reflect Industry expectations, and change the language to reflect what is common to Industry (see Appendix A for example given to participants). To facilitate their changes, a Word version of the survey was sent to the participants, into which they could make edits using the "track changes" feature. Once they had made their changes, they were asked to return the survey to the facilitator, as well as bring a printed version for use at the forum.

\subsection{Phase 3: Forum}

The forum was divided into four stages with each focused on one of the four CEAB attributes: Problem Analysis, Use of Engineering Tools, Ethics and Equity, Economics and Project Management. Participants sat at six separate tables with a maximum of eight participants per table, including at least two Academic representatives. One member of Academia acted as Table Leader and facilitated the table discussions. The other acted as Table Scribe, taking notes, managing the audio recording device (at some tables), and seeking clarifications or elaborations in discussions as required. To maintain anonymity, no names were recorded in the notes or audio recordings.

The goal of each stage was to capture the language and syntax that Industry would use to measure the abilities of new engineering graduates in regards to the four $\mathrm{CEAB}$ attributes, and to obtain Industry's view of what the indicators and competency levels would look like to them. The facilitator initiated each stage from a central position. After his initial comments, the Table Leaders led and managed the discussions. 


\subsection{Data Collection and Analysis}

The results from the three phases of the forum were gathered and used to revise the rubrics to form a language common to both Academia and Industry. The intention is to continue this work by hosting at least two more Industry forums to discuss and revise the remaining eight CEAB attribute rubrics.

Academia values Industry's ideas and opinions, and works to ensure that their comments are captured faithfully and accurately. At each table at the forum, an Academic representative took notes. In addition, some of the discussions were audio-recorded and transcribed at a later date to extract Industry comments. The participants were ensured that no names would be recorded in either the notes or audio recordings in order to maintain anonymity. Prior to the forum, we asked participants if they were comfortable with their discussions being audio-recorded. If for any reason participants chose not to be audio-recorded, we honored that request and made the entire table a no-audio-recording zone (handwritten notes were still taken). None of the participants requested this option.

\section{FINDINGS}

\subsection{General Findings}

Academicians were pleased by the high level of engagement and the animated discussions during the forum. Industry representatives were so engaged that the facilitator (happily) had a difficult time ending one stage so that he could introduce the next. One Industry representative commented that the "forum" approach (the face-to-face interaction between Industry and Academia) stimulated discussions and generated comments that would not have been possible using only a conventional survey or questionnaire.

Industry members commented on the need to define certain terms used in the indicators and the competency levels in the survey, especially for the attribute "Use of Engineering Tools." Without defining the terminology, there is a lack of uniform understanding, and therefore the results of the survey and the assessment of students could be skewed. Additionally, Industry suggested that instructors in the faculty could arrange to fit an industrial lecture into their courses. This would achieve a common understanding of what Industry does, and put course content into context for students and instructors. Industry said they would be willing participants. Upon reviewing these comments after the forum, Academia suggested that Industry could provide guest lectures on the engineering tools that they use. A survey to this end would be beneficial as well.

Industry suggested that the survey could be used as a hiring tool. This would provide continuity and relevance when assessing engineering graduates and the engineering programs in regards to the graduate attributes.

Not all Industry members were aware that there are 12 CEAB graduate attributes. At times, they tried to add some of the knowledge, skills and behaviours that are found in other attributes to the four that were being discussed. Once shown the full list, they were satisfied that some of the areas that were important to them were covered in other attributes. Perhaps, Industry representatives could have been better informed about the $\mathrm{CEAB}$ accreditation requirements and the 12 graduate attributes. In any case, this underscores the need for the development of a common language to cultivate a common understanding for all engineering stakeholders. Industry members expressed their interest in continuing the forums to examine the remaining eight attributes. It was generally agreed that another forum would be held in April 2014 to discuss the next four, and that a subsequent forum would be held to discuss the remaining attributes.

\subsection{Industry's Feedback on the Graduate Attribute Rubrics}

Industry comments for each attribute were organized into five themes that arose from the analysis of Industry's written feedback (Phase 1 and 2) and the discussions during the forum (Phase 3): (I) General Comments; (II) What Industry Wants from New Graduate Engineers; (III) When Industry Hires an Engineer (IV) Suggestions for Wording in the Rubrics; and (V) Competency Levels.

3.2.1 Problem Analysis: Attribute 2. As defined by CEAB, Problem Analysis is "an ability to use appropriate knowledge and skills to identify, formulate, analyze, and solve complex engineering problems in order to reach substantiated conclusions."

\section{(I) General Comments:}

1. Problem analysis and teamwork are tied together.

\section{(II) Industry Expectations of New Graduate Engineers:}

1. To be a team player.

2. To understand how individual problem solving is going to affect others in a larger group.

3. To appreciate other people's perspectives of the problem.

4. To see the problem within the problem.

5. To realize that the problem the individual is solving is part of a larger problem.

6. To recognize his/her role and connection to the larger problem.

7. The ability to ask the appropriate questions of others to solve the problem.

8. The ability to recognize a problem, i.e., Industry doesn't want the design engineer waiting around for someone to bring them a problem to solve.

9. The ability to define the problem.

10. The ability to reflect on and evaluate the problem.

11. To understand where the design solution is most likely to fail.

12. To understand the high cost of failure.

13. The ability to consider problem analysis within a time frame.

14. Technical competence. 
15. The willingness to expose oneself to criticism.

\section{(III) When Industry Hires An Engineer:}

1. They assume that graduates will have low technical skills; they don't assume the graduate will have the skills needed for their Industry.

2. They look to hire team players rather than problem analyzers.

3. They're more interested in professional practice ("soft") skills, and not as concerned with problem analysis skills (an assumption that graduates will have the technical skills, but the professional skills will set them apart).

\section{(IV) Suggestions for Wording in the Rubrics:}

1. Problem with the wording, "proposed solution off the shelf."

2. Define "contextual factors."

3. Use the word "articulate" or "decipher" instead of "construct a problem statement"; or use "decipher" with construct.

4. "Select" instead of "evaluate" potential solutions.

5. A single solution is not an engineering practice. It has to be evaluated. So in hypothesis, propose multiple solutions.

6. Reverse order: evaluation followed by proposal of solutions.

7. The word "practical" doesn't appear enough in the rubrics.

8. What does "feasible" really mean?

9. "Defining the problem": one of the more essential elements on the rubrics.

10. "Play" wasn't touched on in the rubrics: play with problem solving.

\section{(V) Competency Levels:}

1. Level 1 is a completely unacceptable level for graduate hires across the board.

2. Industry is getting level $2 \mathrm{~s}$ and $3 \mathrm{~s}$ in their graduate hires, which is what they want.

3. Level 4 is unreasonable.

3.2.2 Ethics and Equity: Attribute 10. As defined by CEAB, Ethics and Equity is "an ability to apply professional ethics, accountability and equity."

\section{(I) General:}

1. Industry's expectations for ethics and equity are very high.

2. Industry is interested in having our students exposed to ethical case studies.

3. Not interested in the University of Manitoba's "code of conduct."

4. Industry interested in having our students exposed to ethical case studies and risk awareness case studies.
(II) Industry Expectations of New Graduate Engineers:

1. Understand that there are 3 systems of ethics: personal, company, profession.

2. Understand the company's ethics/values.

3. Ability to determine if the company's values align with personal values.

4. Ability to explore contradictions between their own value system, the company's values and/or professional standards.

5. Ability to recognize dilemmas within oneself.

6. Ability to perform due diligence.

7. Ability to negotiate unclear ethical situations where proper resolution is not clear-cut.

8. Ability to take personal responsibility for one's actions.

9. Ability to give appropriate credit when and where credit is due.

10. To understand the concept of non-disclosure agreements.

11. To understand the concept of conflict of interest.

\section{(III) When Industry Hires An Engineer:}

1. Looking for honesty.

\section{(IV) Suggestions for Wording in the Rubrics:}

1. Remove University of Manitoba code of conduct: put in Industry code.

2. Remove "has been caught cheating."

3. Add, "is aware of."

4. Questioned "personal value systems": Should we teach or discuss personal values?

5. A lot of redundancy in indicators.

6. Emphasize accountability.

7. Not inclusive enough.

8. Replace "race" with "ethnicity."

9. Need more conciseness and clarity.

\section{(V) Competency Level:}

1. Level 1 unacceptable across the board.

2. Level 2 should become level 1 .

3. Highest level is 3 .

3.2.3 Use of Engineering Tools: Attribute 5. As defined by $\mathrm{CEAB}$, Use of Engineering Tools is "an ability to create, select, apply, adapt, and extend appropriate techniques, resources, and modern engineering tools to a range of engineering activities, from simple to complex, with an understanding of the associated limitations."

\section{(I) General:}

1. Industry finds a general lack of awareness of where Industry is in terms of engineering tools, which is understandable because Industry moves. Suggestion: Industry representative teaches an annual course on tools used in Industry.

2. Wants Academia to train test engineers. 
3. This attribute tied to lifelong learning: Industry expects graduates to keep learning.

4. Programming is a normal part of Industry's practice.

5. Industry questions whether there are common tools that all students should know and be able to use.

\section{(II) Industry Expectations of New Graduate Engineers:}

1. Exposure to a variety of tools.

2. An understanding of quality of process tools and testing: (i) Software; (ii) Designing tests.

3. Understand the difference between verification and validation.

4. Understand standards.

5. Understand regulations, and regulatory bodies.

6. Understand the principles.

7. Know how to use the right tool for the job.

8. To keep learning.

\section{(III) When Industry Hires An Engineer:}

1. Look for students who have been part of extracurricular team(s). Students with extra-curricular exposure can pull together their understanding of and exposure to different tools.

2. Look for exposure to as many tools as possible, so they can bring their experience to the company.

(IV) Suggestions for Wording in the Rubrics:

1. Need definition of "tools."

\section{(V) Competency Level:}

Understanding of the tools: competency level 2. Use of tools: competency level 3.

3.2.4 Economics and Project Management: Attribute 11. As defined by CEAB, Economics and Project Management is "an ability to appropriately incorporate economics and business practices including project, risk, and change management into the practice of engineering and to understand their limitations."

\section{(I) General:}

1. Did not read like a rubric; too many indicators; not feasible for new graduates.

2. Risk management and mitigation are critical in Industry. A case study course on risk awareness would be beneficial for students. However, each company has its own procedure. Not something Industry would expect of a new graduate.

3. If Industry wanted a project manager, they'd hire one.

4. Teaching this attribute could take away from teaching other important skills.

(II) Industry Expectations of New Graduate Engineers:

1. Awareness of risks, and ability to communicate them.

2. Exposure to the idea of quality process and meeting customers' expectations.

3. Understanding of /exposure to change management.
4. Awareness of/ability to practice time management.

5. Ability to understand financial implications in terms of project management.

(IV) Suggestions for Wording in the Rubrics:

1. No trouble with terminology, just far too many indicators: don't need bidding, leading teams, or risk management.

2. Needs to be more learning-centered: did not read like a rubric.

3. Add workplace health and safety.

4. Separate project management into two levels: to oversee a group, and self-management of one's own role/part.

\section{(V) Competency Level:}

1. Expect level 2, but mostly see graduates with level 1.

2. Perhaps low competency is good enough.

\subsection{Survey Results}

As mentioned, the participants were asked to complete a given survey and return it to the facilitator on or before December 5 . The survey was created in a clickable PDF format. (The results of survey may be obtained from the first author). Fig. 1 shows the competency levels selected for all four attributes. For the most part, Industry representatives chose competency Levels 2 or 3; comparatively few chose 1 or 4 . Notably, Industry favored competency Level 2 over Level 3 by $17 \%$. These data differ from Academia's preliminary response to expected competency levels: they favoured Level 3. This stresses the importance of obtaining a common understanding of engineering stakeholders' perceptions and expectations, and creating a common language to assess engineering students and new graduates.

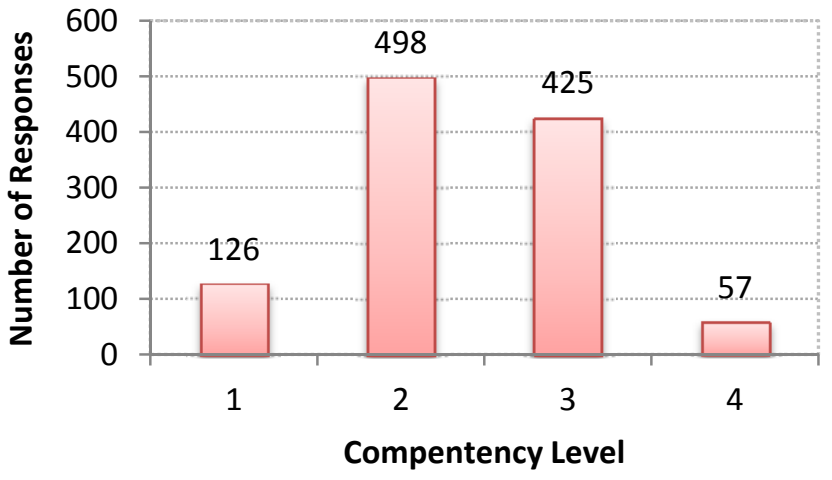

Fig. 1 Results of the Industry survey for expected competency levels.

\subsection{Changes to the Rubrics}

Based on the suggestions made by Industry throughout the three phases of Industry Forum III, changes were made to the rubrics. This section details those changes. 


\subsubsection{Problem Analysis Rubric.}

1. Added, "Identify" to Identify/Define Problem. Used word "articulate" instead of "construct problem statement."

2. Added "Contextualize Problem: Ability to recognize the problem within a larger context (problem within a problem)."

3. Added, "Create" to Propose/Create Multiple solutions. Changed performance level to "Ability to create/play with new solution" to add the concept of "play" to rubric.

4. Expanded "Evaluate Solution Implementation" to include: performance, limitations, cost (time and money), consequences of failure, risk in order to include the concepts of failure, the high cost of failure and consider problem analysis within a time frame.

5. Technical competence covered in Engineering Tools (Attribute 5)/Knowledge Base for Engineering (Attribute 1).

6. Deleted: "proposed solution off the shelf" and "contextual factors" and "feasible."

7. Added, "Select" to "Analyze, Evaluate and Select Potential Solutions."

8. Highlighted proposing "multiple solutions."

9. Clarified order of Propose and Evaluate Solutions.

10. Balanced competency levels.

11. Time Management and Change Management covered in Economics and Project Management (Attribute 11).

12. The ability to accept and use constructive criticism has been added as an indicator to Lifelong Learning (Attribute 12).

13. Elements from Problem Analysis discussion found in Individual and Teamwork (Attribute 6): To be a team player; to understand how individual efforts affect the group; to appreciate others' perspectives.

14. Added "Ask Effective Questions" and "Handle Constructive Criticism" indicators to Lifelong Learning (Attribute 12).

\subsubsection{Ethics \& Equity Rubric.}

1. Group Participation indicator changed to Ethical Issue Recognition and Behaviour indicator. Added reference to three systems of ethics: personal, company, and profession.

2. Developed Equity as a separate indicator and emphasized inclusivity.

3. Removed references to the University of Manitoba code of conduct. Moved references to codes to Professionalism (Attribute 8).

4. Risk analysis found in Economics and Project Management (Attribute 11).

5. Replaced Personal Value System indicator with Accountability indicator: to take personal responsibility's for one's own actions.

6. Ability to give due credit added to Individual and Teamwork (Attribute 6).

7. Removed references to cheating.
8. Edited redundancy; emphasized parsimony, conciseness and clarity. Reduced number of indicators.

9. Replaced "race" with "ethnicity."

10. Balanced competency levels.

\subsubsection{Use of Engineering Tools Rubric.}

1. Added types of tools to CEAB attribute definition in order to define tools. New definition: "An ability to select, apply, adapt, extend and create appropriate tools (resources, software, hardware, techniques) to a range of engineering activities, from simple to complex, with an understanding of the associated limitations."

2. Added understanding the principles and applicability of engineering tools.

3. Added the ability to choose and use relevant tools for engineering activity (know how to use the right tool for the right job).

4. To keep learning is covered in Lifelong Learning (Attribute 12).

5. Reduced number of indicators.

6. Balanced competency levels.

\subsubsection{Economics and Project Management Rubric.}

1. Changed language so that it reads like a rubric, and is learning-centered for students.

2. Reduced number of indicators by 10 . The whole rubric is now under one focus: Project Management and Engineering Economics (rather than four foci).

3. Removed Risk Management focus, and added one indicator: Risk Analysis, emphasizing assessing and communicating risks.

4. Removed Project Management as a separate focus, and worked elements into one focus.

5. Edited redundancy; emphasized parsimony, conciseness and clarity.

6. Added Quality Assurance/Standards and Client Expectations indicator for quality process and meeting customers' expectations.

7. Added Time and Change Management indicator.

8. Added Financial Implications indicator.

9. Removed references to bidding, leading teams and risk management.

10. Personal and Workplace Health and Safety indicator added to Professionalism (Attribute 8).

11. Focused on individual/self-management as defined by CEAB. Rubric could be applied to group.

12. Balanced competency levels and lowered competency level expectations overall.

\section{CONCLUDING REMARKS}

This paper details the processes of and findings from the Industry Forum III, and the changes made to the University of Manitoba graduate attribute rubrics as a result. Industry members from 30 companies and 17 Academics met in 
December 2013 with the singular goal of improving engineering education, a testimony to the ongoing partnership between local Manitoba Industry and Academia from the Faculty of Engineering at the University of Manitoba. Findings underscored the diverse perspectives and expectations of Industry and Academia in regards to the indicators used to define the 12 CEAB graduate attributes, as well as to the competency levels targeted. Additionally, the language used by Academia was found to be different than the language used by Industry. This forum, the third in a sequence of Industry forums held so far, initiated work to establish a common language that both partners can agree upon to assess the knowledge, skills and behaviours of engineering students and new engineering graduates and hires from the University of Manitoba with the aim to create a common understanding and set of expectations. This process is a part of the faculty's cycle of continual program improvement, and is a covenant between Academia and Industry to ultimately graduate more productive, efficient and competitive Industry-ready engineers.

\section{Acknowledgements}

We would like to thank our Manitoba Industry partners, Friends of Engineering and the members of Academia for participating in this event. We would also like to thank the Dean's Office of the Faculty of Engineering at the University of Manitoba for their support.

\section{References}

[1] N. Mukahark, N. Wahid, Z. I. Rizman, M. A. Ali, M. A. Aris, E. A. Kadir and G. K. S. Nair, "Industry's feedback of new diploma program in industrial engineering," World Applied Sciences Journal, pp. 103-108, 2013.

[2] "Industry Profiles, Engineering Industry Profile Graduates.," [Online]. Available: http://www.grb.uk.com/engineeringindustry-profile. [Accessed 12 April 2014].

[3] K. Lowden, S. Hall, D. Elliot and J. Lewin, "The, Employers' Perceptions of Employability Skills of new Graduates, London, ENGLAND: Edge Foundation," 2011. [Online].

Available: http://www.edge.co.uk/media/63412/employability_skills_as _pdf_-_final_online_version.pdf. [Accessed 12 April 2014]].

[4] B. E. Newbury, "Speaking in tongues: the gap between academic language and industry language," in 'Language in the disciplines: disciplinary discourses and the embedding of academic literacy skills within programs', an Academic Literacy Teaching and Research Network (ALTAR) Symposium, Hawthorn, Victoria, Australia, 24 November 2010.

[5] Engineers Canada, "Accreditation Resources | Engineers Canada," [Online]. Available: http://www.engineerscanada.ca/accreditation-resources. [Accessed 14 April 2014].

[6] J. McGourty, C. Sebastian and W. Swart, "Developing a comprehensive assessment program for engineering education," Journal of Engineering Education, vol. 87, no. 4, pp. 355-361, 1998.

[7] G. M. Rogers, "EC2000 and measurement: How much precision is enough?," Journal of Engineering Education, vol. 89, no. 2, pp. 161-166, 2000.

[8] N. Soundarajan, "Preparing for accreditation under EC 2000: An experience report," Journal of Engineering Education, vol. 91, no. 1, pp. 117-123, 2002.

[9] J. Shaeiwitz, "Outcomes assessment in engineering education," Journal of Engineering Education, vol. 85, no. 3, pp. 239-246, 1996.

[10] J. Seniuk Cicek, S. Ingram, N. Sepehri, J. Burak, P. Labossiere, D. Mann, D. Ruth, A. Parker, N. Godavari and K. Ferens, "Rubrics as a Vehicle to Define the Twelve CEAB Graduate Attributes, Determine Graduate Competencies, and Develop a Common Language for Engineering Stakeholders," in CEEA Canadian Engineering Education Conf., CEEC14, Canmore, AB, 8-11 June 2014.

\section{APPENDIX A: Example Given To Participants Phase 2}

For each of the chosen CEAB attributes please identify several indicators. An indicator is a measurable descriptor of what new engineering graduates should be able to do, to be considered competent in an attribute. For example, the following (Problem Identification) is a measurable descriptor of the CEAB "Problem Analysis" attribute:

CEAB Attribute: Problem Analysis

Indicators (of Problem Analysis)

1. Problem Identification: When presented with a complex ill-structured problem, new engineering graduates should be able to identify known and unknown information, uncertainties, and biases.

\section{Your next indicator}

In addition, for each indicator of an attribute, please identify four levels of competency for that indicator. The competency levels should be stated in terms of your expectations of a new engineering graduate. Continuing with the above example, examples of the four levels of competency can be stated as: Unacceptable, Marginal, Meets Expectations, and Exemplary. For each one of the competency levels you create, please provide a description. For example:

Unacceptable: The graduate is not able to extract the known information from the given description of the problem. Also, the graduate is not able to identify the missing information. Also, the graduate is not able to able to recognize the uncertainty of the given problem.

Marginal: The graduate can extract the known information from the given problem description, and identify some of the missing and uncertain information.

Meets Expectations: etc.

Exemplary: etc. 